\title{
OTRA POLÍTICA VISUAL DE LA REPRESENTACIÓN SEXUAL: EL PORNO FEMINISTA DE ERIKA LUST
}

\author{
ANOTHER TYPE OF SEXUAL BODY POLITICS: \\ ERIKA LUST'S FEMINIST PORN \\ TXetxu Aguado \\ Dartmouth College \\ txetxu.aguado@dartmouth.edu
}

RESUMEN: Lo que se ha venido en llamar postporno feminista remite a una política visual del cuerpo donde su representación convencional (con la ocultación de sus partes consideradas inapropiadas) como la pornográfica (con la explotación reificada y comodificada del cuerpo) no encuentran asiento. La estética de los filmes postporno de la directora residente en Barcelona Erika Lust se deslinda tanto del cuerpo oculto bajo la capa gruesa de los tabús morales como se aleja de la violencia de su máxima exhibición y cosificación bajo el paradigma pornográfico.

PALABRAS CLAVE: neoliberalismo; patriarcado; pornografía feminista; Lucía Egaña; Erika Lust

ABSTRACT: What has come to be world-wide known as feminist porn puts forward a visual body politics that turns down both traditional body representations (always veiling masculine and feminine genitalia in order to be considerer proper) and sexist pornographic images (with its gynecological approach to the body). The aesthetics involved in the post-porn films by Barcelona resident director Erika Lust are not interested in hiding the body under a thick layer of moral taboos nor in the violence of its maximum exhibition (and objectification) under the traditional porno paradigm.

Keywords: Neoliberalism; Patriarchy; Feminist Porn; Lucía Egaña; Erika Lust

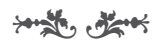


¿Se cae en una contradicción irresoluble cuando se quieren filmar imágenes pornográficas que al mismo tiempo sean feministas, es decir, sin humillaciones ni degradaciones de cuerpo alguno? La directora residente en Barcelona Erika Lust no lo cree así. El porno no machista de sus películas remite a una política visual del cuerpo ajena a la mirada moralizante que lo oculta y a la mirada pornográfica que lo cosifica. Los personajes de sus películas se encuentran a gusto con sus cuerpos, con sus fluidos y con los deseos que los incitan a explorar su sexualidad y a descubrirla de la manera más emocionalmente satisfactoria. De aquí, el permanente roce y contacto con los demás, la exploración con el tacto y la palabra, o el diálogo con el otro, que no es más que preparación para resignificar sexualmente el cuerpo sin constreñirlo.

A continuación, se analizará la combinación fílmica entre pornografía y feminismo. Primero, se comenzará con unas reflexiones sobre neoliberalismo económico y sexualidad. En segundo lugar, se constatan las implicaciones del postporno queer de Paul B. Preciado. Finalmente, se estudia el recorrido de los filmes de Lust para elaborar imágenes del cuerpo y de su dimensión sexualemocional novedosas dentro de lo que se ha venido en llamar porno feminista.

\section{El neoliberalismo sexual}

La actual crisis es una de ausencia de representación, por no decir expulsión o erradicación, de todos aquellos que cuestionan con sus ideas o actitudes lo existente. Se priva de presencia en el espacio público a quien no es necesario para legitimar lo neoliberal, en lo económico y lo patriarcal, en lo sexual y social. ${ }^{1}$ Patriarcado y neoliberalismo vienen juntos; el uno se refuerza con el otro, y viceversa. Así, se ridiculiza la idea de una economía enfocada hacia las necesidades sociales de todos, y no solo hacia los beneficios de unos pocos. Se deslegitiman las voces alternativas con seudo democracias en contra de quien no siga las directrices de la oficialidad de los partidos. Se demonizan las expresiones sexuales fuera de los modelos al uso religiosos o estatales, siempre a favor de un sexo seguro y reproductor. El escenario actual se define, entonces, con una economía cuyo principio rector es la maximización de beneficios, siendo compatible con una llamada democracia para los pocos y con definiciones sobre lo sexual donde lo heteronormativo y lo sexista son las únicas maneras de pensar el deseo y el placer.

Un área de trabajo para revertir esta situación se relaciona con la producción de conocimientos - discursos, narrativas, historias visuales, imaginarios simbólicos, gestualidades- críticos con lo actual. Estos conocimientos no se producirán solamente en las universidades ni en los laboratorios ni en los think

\footnotetext{
1 Una definición operativa de patriarcado para esta discusión la proporciona bell hooks en su Feminism is for Everybody, cuando lo define como "sexismo institucionalizado" (2000: IX). El sexismo se legitima como lo normal, lo adecuado, lo natural. Se hace lo mismo con el neoliberalismo cuando se lo toma como el único modelo económico. La explotación neoliberal en lo económico viene pareja con la explotación -el sexismo- en lo sexual, ciertamente, pero también en las relaciones laborales, sociales o domésticas.
} 
tanks asociados al poder, todos ellos bien financiados por las grandes empresas globales. Los conocimientos alternativos nunca se darán por terminados; se querrán abiertos a la constante modificación y a las influencias externas. Tampoco serán jerárquicos: se aceptarán críticamente las aportaciones de cualquiera en su elaboración. Por un lado, los discursos alternativos van a informar el activismo político para reinventar lo democrático con la mejor representación para lo ignorado, ya sean personas o ideas. Por otro lado, el activismo político incluirá el componente sexual, dirigido a la liberación del cuerpo de lo heteronormativo y patriarcal.

No se trata de sustituir un deseo por otro, ni una jerarquía sexual por otra, dentro de lo ya conocido. Se está abogando por la exploración y el descubrimiento de lo diferente, donde se privilegie lo caótico, lo errático o lo incoherente frente a lo estrictamente ordenado, dirigido y coherente. Los conocimientos a producir no son más de lo mismo, cuya única diferencia, si es que la hubiera, fuera de matiz. Su vocación es la de ser alternativa, contextualizada en el tiempo, pero alternativa radical. Por eso, estos conocimientos a elaborar no operan dentro de los paradigmas cotidianos, sino que los revientan para arrinconarlos como si fueran escombros y facilitar el alumbramiento de lo nuevo. Pero lo nuevo también puede quedar en teatralidad sin recorrido político o sexual crítico, es decir, en un simple efecto de superficie sin molestar al patriarcado sexual o el neoliberalismo económico. Quizás ocurra así en la mayoría de los casos; en otras ocasiones, atisbará el cambio más allá del juego estético o de la pose política o sexual novedosa.

Se están reclamando discursos en contra de lo hegemónico, enfocados hacia lo que podrían denominarse excesos sin utilidad alguna, esto es, áreas incapaces de ser asimiladas o manipuladas en la afirmación de lo que ya existe. Dado el potencial contestatario y subversivo de la realidad, estas áreas de exceso conformarán los cimientos de una economía-sexualidad libidinal frente a una economía-sexualidad neoliberal, regulada por el beneficio o la reproducción. Lo libidinal se dirigirá a la mejora de la vida en general, no favoreciendo lo que incrementa las ganancias pecuniarias de las corporaciones, pero a favor de todo aquello que protege el existir humano en los contextos ecológicos, y sexuales, que lo han sustentado a lo largo de los siglos. ${ }^{2}$ Lo libidinal no puede obviar los desastres medioambientales como consecuencia de las ideologías del crecimiento sin límite. El planeta Tierra es bastante más que una despensa de recursos susceptibles de producir beneficios.

La resistencia vendrá de la mano del rechazo contundente del neoliberalismo. Vendrá por igual de la recuperación, o elaboración, novedosa de relaciones con el entorno natural y humano menos depredadoras. Se quiere desarrollar más lo relacional y la mutualidad, lo compartido y la colaboración, en contra de la competencia y la exclusión, lo privado a ultranza y la oposición. Estas relaciones

\footnotetext{
${ }^{2}$ La referencia se toma, claro está, de Jean-François Lyotard y su Économie libidinal (1974), aunque se la interpreta de manera libre y, sobre todo, se la politiza.
} 
son ajenas al uso instrumental de las personas entre sí. ${ }^{3}$ De la misma forma que la resistencia se opone a la compra de trabajo en condiciones de semiesclavitud en los mercados globales, se opone a la compra de trabajo sexual en la prostitución o en la pornografía. El deseo y la sexualidad no se definirán por el abuso de algún otro ser humano con la finalidad de extraer placer vía la vejación en la prostitución o la pornografía. En el neoliberalismo, estas dos últimas, e incluso el erotismo, ${ }^{4}$ se enfocan en exclusividad en los genitales de otros, separándolos del resto del cuerpo, para explotarlos y aumentar su rendimiento orgásmico como si se tratara de un beneficio económico más. Frente a esto, es posible considerar el cuerpo como unidad material y emocional: todo él en su conjunto, o cualquier parte del mismo ligada a las demás, es capaz de recibir y dar placer. ${ }^{5}$ Volver a tomar el cuerpo como un todo supone repensar libremente todas y cada una de sus partes, de los fluidos y excrecencias, de sus movimientos, de sus poses, así como los entramados emocionales personales y relacionales con los demás. Se dice libremente sin menoscabo de que la exploración quede sujeta a un marco de no violencia personal o infligida a otros, y fundada en el consentimiento.

La resistencia significa por igual hacer frente a la pérdida de la materialidad del cuerpo en el mundo virtual de preponderancia extrema de las imágenes. Cuando el cuerpo se descompone en bites, pierde su complejidad a favor de la facilidad de la transmisión en las redes. Ahora, el cuerpo no se fragmenta solo por la fijación obsesiva en algunos de sus órganos y glándulas, principalmente las más convencionalmente sexualizadas. Con su desmaterialización, la unidad de carne y huesos que lo sustenta pierde realidad a favor de la imagen que se comunica. El cuerpo, el material que lo informa, se torna evanescente, desaparece. Interesa más el aspecto de una pose, de un mohín, de una torsión, de una sonrisa, que la combinación de músculos y emociones para producirla. En lo pornográfico, interesa más la postura imposible, la fricción de cuerpos inusitada,

\footnotetext{
3 De hecho, la instrumentalización, entendida como "la destrucción de la singularidad humana", siguiendo a Adriana Cavarero, no solo define la situación de horror sino también la ausencia de "cualquier responsabilidad ética o política" (2009: 52). Esta ausencia de responsabilidad sería la propia del neoliberalismo económico y sexual como aquí se lo define. Todas las traducciones son propias.

${ }^{4}$ La distinción entre lo erótico y lo pornográfico depende de quien contempla sus expresiones. Lo habitual es señalar la expresión sexual explícita, cruda, como propia de lo porno mientras lo erótico se dedicaría a la estilización artística. Es problemático establecer una separación estricta entre los dos por cuanto lo que entra en juego son los valores morales y estéticos de quien clasifica y no un criterio claro de separación. La bibliografía sobre este tema es muy numerosa. Una buena discusión es la recogida por Julie Lavigne en el capítulo 1 de su La traversée de la pornographie (2014).

${ }^{5}$ Más allá de la pornografía, reapropiarse del cuerpo significa no ocultar los orificios de entrada y salida, así como sus secreciones. Las aperturas corporales dejan de invisibilizarse bajo la vergüenza del tabú moral o médico, como lo inapropiado socialmente, en el primer caso, o como lo contaminante vírico en el segundo. Para Julia Kristeva, las sustancias emanadas del cuerpo se asocian inmediatamente a todo lo que lo contamina, da igual que se hable de la leche materna o de otras secreciones o incluso supuraciones (1982: 53). La filósofa citará la leche materna como la primera toma de contacto con lo abyecto (3), esto es, con lo contrario a lo definido como masculino y puro, sin contaminación femenina alguna. Se trataría de poner de lado estas conexiones.
} 
o las embestidas desmesuradas, que el esfuerzo físico y el desgaste emocional necesarios para conseguirlas.

Es compresible que Paul Virilio, en su Cybermonde, la politique du pire, propugne la "reapropiación del cuerpo", volver a materializarlo (1996: 48). Pero también se ha de materializar el mundo que lo sustenta. Materializar el cuerpo supone prestar atención al conocimiento adquirido con los sentidos, a las emociones elaboradas vía la relación con los demás y con el entorno físico. La sexualidad involucra la emoción y sin ella, el placer se resigna a ser solo un efecto artificial, sin la imaginación necesaria para dotarlo de profundidad. Un cuerpo sin materialidad es simple apariencia. Por su parte, sin la materialidad del mundo, es decir, sin las resistencias espaciales y temporales para moverse de un lugar a otro, sin el contacto con lo ecológico, el planeta queda reducido a virtualidad por la cual navegar. Desaparece el interés pausado del viajero y su aprendizaje de los lugares que visita a favor del turista y su consumo de la banalidad de fantasías culturales.

Para Paul Virilio, el contacto entre personas, incluidas las relaciones sexuales y necesariamente a través de la corporalidad, se centran en exclusiva en la coreografía, cuando se trataría de desarrollar la sociografía (1996: 44). Se aboga por la sociografía porque más que un único paso de movimiento coreográfico, individualizado, interesa la totalidad de la composición figurativa y dinámica de todos en la danza. La sociografía exige un acercamiento a los demás donde dejen de ser un instrumento sexual o un mero "objeto excitante", como señala el filósofo alemán Byung-Chul Han (2014: 24). Para este último, el amor, como el momento sociográfico de Virilio, no puede quedar asimilado a simple manifestación sexual, ya sea erótica o pornográfica. Solo el amor es digno de consideración porque, con las palabras de Alain Badiou en su In Praise of Love, se da a luz a un algo, un evento "que no está presente en el orden inmediato de las cosas" y "persiste y perdura" (2012: 29). Para Badiou el evento amoroso abre la realidad, la enriquece, añade complejidad, da existencia a lo que previamente al evento no tenía lugar.

Ciertamente, el amor de Byung-Chul se opone a la cuantificación placentera o al rendimiento orgásmico neoliberal del cuanto más, mejor. Para él, por el contrario, la pornografía sería la versión neoliberal del amor. Sin embargo, la concepción de Byung-Chul de la sexualidad explícita es un tanto estrecha, pues se fija en sus manifestaciones más sexistas y misóginas, esas donde el otro es instrumento de placer. Da más importancia al amor, como el sentimiento más excelso, que a su posible manifestación material en lo sexual. Incluso, su acercamiento a la pornografía bebe en abundancia de una visión timorata tanto del amor como de la sexualidad. Ambos, amor y sexualidad, parecen haber sido normalizados en la pareja hombre y mujer, y en prácticas sexuales seguras consistentes en poco más que la penetración vaginal. El autor no tiene en cuenta que la exploración de cauces sexuales no convencionales -lo propio de la postpornografía- puede ser la fuente del evento amoroso de Badiou. Por no decir que la sexualidad más explícita puede forzar la aparición del evento amoroso 
lejos del amor romántico de palpitaciones y pérdidas de apetito que, por otro lado, ni Badiou ni Byung-Chul defienden.

Michela Marzano parece tener el mismo problema que los dos filósofos anteriores cuando no diferencia entre manifestaciones pornográficas. En verdad, la mayor parte de la pornografía no consigue ir más allá de la presentación de un cuerpo fragmentado en boca, pechos, genitales y ano (2003: 201), rebozándolo con el espectáculo de la abyección a la que se somete a los demás (206). En términos de Virilio, se diría que lo pornográfico para Marzano es únicamente coreografía de trozos de carne sin relación de pertenencia al cuerpo del que provienen. Pero el problema no es la crítica de Marzano o de Byung-Chul de lo pornográfico. Se puede estar de acuerdo con ella y señalar, al mismo tiempo, lo problemático de su acercamiento: la generalización de toda experiencia pornográfica como machista y degradante, enfocada a la consecución de la máxima exhibición y la máxima excitación, lo que se viene denominando concepción neoliberal del placer.

Es patente la vocación autoritaria de modelos de amor y sexualidad que se quieren universales cuando en realidad son unos más entre otros posibles, como la heteronormatividad. También es indudable el autoritarismo del reverso de este amor y sexualidad tradicionales en la forma de la pornografía sexista, cuyas obsesiones por la hipervisibilidad, la dominación y control de algún cuerpo se erigen en modelo único de excitación sexual. ${ }^{6} \mathrm{Al}$ margen de la sexualidad normalizada en matrimonios al uso o en pornografías machaconamente machistas, y de dudosa novedad en sus planteamientos, se sitúa lo que ha venido en denominarse post-porno: un porno ajeno a las convenciones y fantasías de dominación sexista del porno tradicional. El post-porno propone abrirse al potencial sexual del cuerpo, sin renegar a priori de ninguna práctica o postura, explorando las combinaciones emocionales y materiales que más puedan satisfacer. Aboga por prácticas sexuales explícitas, porque lo suyo no es un planteamiento teórico o abstracto sino práctico y concreto.

\section{Paul B. Preciado, lucía Egaña y el postporno}

Para el teórico del post-porno Paul B. Preciado, "la verdad del sexo no es desvelamiento, es sex design" (2008: 34), es decir, no hay una verdad más auténtica que otras sobre el sexo; no hay un posicionamiento más correcto o más políticamente adecuado. Importa únicamente lo que sea más satisfactorio para cada uno. La identidad sexual y la sexualidad que cada cual quiera practicar la diseñará según sus preferencias, gustos, inclinaciones. Siguiendo a Preciado, el modelo de producción de placer del momento actual es el farmacopornográfico

\footnotetext{
6 Linda Williams definió la hipervisibilidad con la expresión afortunada de "frenesí por lo visible", por ese no dejar nada al arbitrio del misterio (1989: 38). Con un tono similar, Giorgio Agamben equipara la desnudez con la pérdida de lo cognoscible: cuando un objeto o sujeto participa de la total transparencia, no hay nada más que conocer de él (2011: 104). Para Byung-Chul, la imagen porno conjuga la hipervisibilidad con la espectacularidad, porque busca la máxima difusión y exposición (2013: 12), es decir, la producción de máxima excitación sin matiz alguno.
} 
(2008: 32): fármacos para moldear el cuerpo según las apetencias y deseos del género, y pornografía para explorar y dar contenido a los deseos. El modelo del placer no es el fordista de la fabricación en cadena de unos mismos placeres homogéneos iguales para todos, independientemente de la diversidad de gustos sexuales. En el régimen farmacopornográfico, cualquier droga, sea legal o ilegal, se usará para conformar el cuerpo y diseñarlo según la configuración más propicia al desarrollo del placer. Y el abanico de placeres, sus múltiples por no decir infinitas combinaciones corporales y emocionales, se perfilará en la producción pornográfica o, mejor dicho, en la post-pornográfica. ${ }^{7}$

En el régimen farmacopornográfico de Preciado, la fuerza de trabajo ya no se asocia a ese desgaste físico de energía del trabajador empleado en la producción de un objeto. La fuerza de trabajo, como el común denominador a toda la producción o como el elemento más elemental al cual toda mercancía se reduce, pasa a ser la "fuerza orgásmica" (2008: 32). Esta fuerza orgásmica se define como la energía para la producción de orgasmos contenida en toda mercancía pornográfica. Más que un desgaste físico o intelectual, como en la fuerza de trabajo marxista, se está hablando de la capacidad para facilitar el orgasmo contenido en todo producto farmacopornográfico. Si la acumulación de riqueza antes consistía en el almacenamiento de fuerza de trabajo traducido a capital, ahora la acumulación de fuerza orgásmica se traduce así en capital "eyaculante" (2008: 43), y no en capital financiero o fijo.

El placer orgásmico de Preciado, y el diseño del cuerpo a medida gracias a los fármacos y la semiótica porno, se postula a contracorriente de esa sexualidad tradicional enfocada en la procreación. La búsqueda del placer en contra de los discursos hegemónicos sobre el deseo o la sexualidad lo denominará Preciado "contrasexual". En lo contrasexual, la naturaleza no discriminará entre mujeres y hombres según su biología sexual (2011: 13). Si el cuerpo es "polisexual"(2008: 39), el género se definirá, citando a Teresa de Lauretis, como "una construcción socio-cultural [...] un cruce de representaciones discursivas y visuales" (2008: 83). ${ }^{8}$ El género será "una gestión del cuerpo" (93), una interrelación entre los deseos y las posibilidades de su alumbramiento en el régimen de la fuerza orgásmica. Y la heterosexualidad, antes la norma de comportamiento sexual universal, pasa a ser "una estética farmacopornográfica entre otras" (98), y sin jerarquía alguna entre ellas.

\footnotetext{
7 En el film de la artista Shu Lea Cheang, I.K.U. (2000), el personaje androide, a través de sus múltiples transformaciones, recoge información sobre los orgasmos y fantasías sexuales de todos aquellos con quien se relaciona. Esta información se subirá a la red para que los clientes de la empresa para la que trabaja puedan bajarlos y usarlos como estímulo sexual. Este personaje, y sus artilugios técnicos, provee imaginarios de porno prácticamente ilimitados. Rellena de contenido la parte porno del régimen farmacopornográfico de Preciado.

8 En palabras de Lauretis, "la oposición sociocultural entre 'mujer' y 'hombre'" es el momento fundacional de lo heterosexual donde "el género o la división social es no visible, como si fuera un punto ciego, o [es] asumido a priori" (1990: 130). Por el contrario, las apreciaciones teóricas de Preciado, siguiendo en este lugar a de Lauretis, tornan visible y desmontan el reclamo heterosexual de dos únicos géneros, el de un hombre y una mujer.
} 
En el acercamiento de Preciado al deseo, sexualidad y género, si el género es una estética más entre otras posibles, dependerá del buen entender de cada cual, al configurarlo, y además sin limitación alguna. Las constricciones a la libertad de género dependerán únicamente de lo posibilitado por los fármacos y los contenidos porno. No obstante, ya Judith Butler llamaba la atención sobre cómo el género es un "hacerse", una "práctica de improvisación en un escenario de restricciones" (2004: 1). El género resulta de la tensión entre el deseo individual por ser y el reconocimiento social que no siempre se obtiene y que define las restricciones. Entre ambos términos se sitúa la improvisación, pues el camino a seguir por el deseo en el contexto de las limitaciones sociales tiene mucho del método de probar, rechazar y volver a probar si no ha funcionado; de aquí la importancia de la improvisación. La tensión no tiene por qué resolverse bien a cada momento, pues implica un constante hacerse y deshacerse, un constante navegar entre lo posible y lo imposible, o en extremo difícil, en todo momento.

El acercamiento de Preciado, y lo farmacoporno, incide más en el potencial del deseo individual para configurar el género que en las trabas sociales para impedírselo, que no parece haber ninguna. El género se torna en una parada momentánea, en un fluir continuo de infinitas elecciones. Si los fármacos y lo porno caen en manos de la mercantilización, es decir, si la generación de variedades farmacopornográficas se circunscribe a las facilitadas por los mercados neoliberales, se termina con un género queer superficial porque las opciones ofrecidas han de ajustarse a los estándares de venta en las estanterías de los supermercados. ${ }^{9}$ Las sexualidades y géneros diversos e inagotables quedan reducidos a meras variantes del mismo producto de consumo. Se estaría ante un género, si se permite la expresión, de usar y tirar. Se pierde la carga contestataria sobrevenida en ese desdibujar las fronteras tradicionales del género masculino y femenino. El escenario es fácil de imaginar. Se diluye la aspiración política a revolucionar el deseo. Lo político quedaría constreñido a una ampliación de la estrecha banda de lo ya conocido en materia sexual. Desaparece el revulsivo de la apuesta radical por el género queer con sus cargas de profundidad críticas contra todo lo que se encuentra convenientemente domesticado. Lo queer puede terminar como simple espectáculo circense o mero producto orgásmico de consumo. $^{10}$

Al margen de estas críticas, el documental de Lucía Egaña, Mi sexualidad es una creación artística (2011), se inserta en la corriente postpornográfica o porno queer o régimen farmacopornográfico de Preciado. El documental se organiza en torno a entrevistas y visionados de performances post-porno de activistas $\mathrm{y}$ artistas que en la actualidad o alguna vez han estado ligados a la escena queer

\footnotetext{
9 Jean-Luc Godard plasmó esta contradicción irresoluble entre un programa comunista de cambio radical y su puesta a la venta, además rebajado, en un centro comercial. En su película, Tout va bien (1972), en la escena del supermercado, el programa radical está en oferta, como si fuera un producto más de consumo, indistinguible de los demás.

10 Judith Butler es más contundente en su crítica cuando afirma que con la tecnología, como la entiende Preciado en este texto, "se corre el riesgo de que lo humano se convierta en nada más que en un efecto tecnológico" (2004: 11).
} 
en Barcelona. Se filma a grupos tan diversos como Quimera Rosa, Post-op, Go Fist Foundation, o a artistas como María Llopis o Diana Torres. A los artistas se les hace preguntas ante la cámara, donde reflexionan sobre su trabajo sin academicismos ni obtusas abstracciones. Entienden sus intervenciones como prácticas concretas para desestabilizar lo patriarcal y para descentrar a los espectadores. Se vendrá a cuestionar los fundamentos de la heterosexualidad como modelo único de lo sexual. En esta línea, la estética del documental y de sus protagonistas, los temas tratados, las performances mostradas, la interacción con el público, la iluminación, los escenarios, el lenguaje utilizado, el rechazo de la profesionalización al uso, la ruptura con la normalización de lo sexual y del placer, la vocación de escandalizar, el rechazo de la mera pose teatral o espectacular, la apuesta por la autenticidad en las representaciones, o el activismo con finalidad de transformación política, asociarían este film a lo punk.

Esta estética y este posicionamiento cultural y político vienen muy a propósito de la intencionalidad del documental. En palabras de Egaña, lo postporno "aparece entonces como una herramienta de análisis, un dispositivo cultural, y un campo en el cual se ve posible la (re)creación de nuevas identidades y maneras de representar el deseo" (2009: 11). Se desmontarán con violencia figurada, pero expresa en el escenario, los imaginarios corporales implícitos en el matrimonio entre un hombre y una mujer heterosexuales, el amor romántico, el sexo con finalidad procreadora, o el sexo vaginal en exclusiva. Se cuestionará la ausencia de placer, el deseo unidireccional y sin matices de algunos hombres, las prótesis técnicas reproductivas o la tecnificación del cuerpo para compensar sus carencias sexuales. Las actuaciones hacen patente la enorme violencia simbólica y visual, o las tremendas discriminaciones y frustraciones, latiendo bajo la superficie de lo sexual sancionada por religiones y estados. Como dice Diana Torres, la representación "puede ser más o menos violenta en función del nivel de lavado cerebral o de represión de quien lo presencia" (2011: 66). Cuanto más normal esté considerado un comportamiento, mayor será la violencia simbólica requerida para desnaturalizarlo. Lo mismo ocurre con esos espectadores que han creído y seguido lo heterosexual sin mayores complicaciones: se sienten vulnerables y se hacen descreídos. Y, sin embargo, este es el propósito de las performances del documental de Egaña.

Diana Torres explica con claridad qué se ataca: lo hetero y quienes lo defienden, asimilados a lo trasnochado o lo muerto. También explica quiénes son los que atacan: todos los que no encuentran acomodo en lo heteronormativo. Dirá Torres, "nosotrxs, Ixs mutantes, las putas, las marimachas, las transgénicas, iremos a vuestras tumbas a profanarlas, a follar sobre ellas, a mearnos, a corrernos, a pulverizarlas" (2011: 78). La conculcación del dimorfismo sexual -la separación estricta entre hombre y mujer- se lleva a cabo por quien es desplazado a la marginalidad sexual: todos "Ixs nosotrxs" (78). En la representación se habla del "follar" o del "correrse", donde el lenguaje profana el romántico "hacer el amor" o el médico, o más aséptico, "alcanzar el clímax". La presencia de excrementos, de la orina, de la sangre, del vómito, de la saliva, de todos y cada uno de los fluidos corporales formará parte de las performances de Diana Torres. De 
manera figurada o real, la puesta en escena de estos fluidos en su forma líquida o sólida es una visualización del cuerpo distinta. Esta visión no está mediada por la seguridad ni la comodidad acrítica de lo que es conveniente no mostrar u ocultar. En esta mirada al cuerpo no intervienen ni los discursos médicos sobre la higiene o la desinfección, y su corolario en la salud, ni los discursos morales a favor de la ocultación de lo menos noble del cuerpo. Al hacer visibles dichos fluidos es cuando se cuestiona el olvido de lo corporal del cuerpo, o de su materialidad que se ha idealizado hasta el extremo de hacerla irreconocible. ${ }^{11}$ En la performance de Torres se vuelve al cuerpo con todas sus consecuencias, en una interpretación posible de la llamada a la "rematerialización" y "reapropiación" de Paul Virilio (1996: 48).

Igualmente, se eliminará la moralina visual que condena a los órganos sexuales a quedar recluidos en la penumbra de las alcobas. Contrariamaente a la hipervisibilidad del porno tradicional, al mostrar los genitales en su belleza sin recurso a tapujos se revierte el oscurantismo, o el pecado, asociados a la búsqueda del placer individual o colectivo. Torres y sus personajes se masturbarán en público sin remilgos a la hora de mostrar su satisfacción. ¿Por qué la capacidad para el placer, característica de todos los cuerpos, debe confinarse a la invisibilidad de lo privado? El "follar" delante de los espectadores para los activistas de Quimera Rosa es ajeno al exhibicionismo de quien cree poseer órganos espectaculares o al reconocimiento narcisista de quien se cree el mejor amante. Al hacerlo en público, tanto en un escenario como en un parque público en Barcelona, se vuelve a dotar a los espacios teatrales, a las plazas, o los parques o jardines, de su antigua importancia pública para la confrontación, la comunicación o el diálogo entre pareceres disímiles. ${ }^{12}$

El piercing de pezones, penes o labios vaginales, entre otros, de Torres, Llopis o Go Fist Foundation, no solo reformula, e incluso potencia, las zonas erógenas del cuerpo, sino que se atreve con la introducción de prácticas sadomasoquistas, aborrecidas sin matiz alguno por el sexo saludable. El grupo Quimera Rosa se acercará al sexo anal masculino de la mano de juguetes. Para Go Fist Foundation, la juguetería sexual será el instrumental ineludible del descubrimiento de todo el cuerpo, y no solo de sus genitales, para el placer. La tecnificación del cuerpo de Go Fist Foundation es la que se sitúa más certeramente en la órbita de las teorías de Preciado. Y no podía faltar la presencia en el documental de la activista feminista y gran reina del post-porno, Anne Sprinkle. ${ }^{13}$

\footnotetext{
11 En la película de Catherine Breillat, Anatomie de l'enfer (2004), el personaje femenino embadurna con la sangre de su menstruación los genitales del actor de cine porno más sexista, Rocco Siffredi. Mientras a la corporalidad femenina se la invisibiliza bajo los mil y un tópicos sobre la belleza de su cuerpo, lo masculino la horada sin problemas para su placer. Cuando la mujer exige al hombre reconocer su sangre menstrual, este escapa asombrado y asqueado. Su placer se ha visto frustrado. El cuerpo femenino seguirá sin ser visible.

12 De hecho, será en el escenario público de las calles de la ciudad o privado en un teatro donde se haga realidad la máxima queer: "el propio cuerpo se convierte en una obra de arte y la propia vida en una novela" en palabras de Kim Pérez (2010: 107). Pérez enfatiza la dimensión performativa de la definición, o la indefinición, sexual.

13 Otro documental a base de entrevistas a la escena postporno barcelonesa es el de Virginie Des-
} 


\section{ERIKA LUST Y EL PORNO FEMINISTA}

Virilio proponía la vuelta al cuerpo. Byung-Chul criticaba la reducción de los demás a objeto de excitación. Marzano señalaba la fragmentación extrema del cuerpo en unas cuantas glándulas y órganos en el enfoque pornográfico. Si se hiciera caso a estos análisis, la representación explícita de la sexualidad quizás no llegase a producir el evento amoroso de Badiou, pero ciertamente caminaría por derroteros muy distintos a los más convencionales. Ahora bien, las películas de la directora de origen sueco residente en Barcelona, Erika Lust, no tratan de producir una novedad sexual sin relación alguna con lo previamente existente, en línea con lo propuesto por Badiou, y a la que el documental de Egaña da una respuesta acertada. Ni tampoco quieren diseñar el cuerpo sexual, como proponía Preciado, a base de fármacos y de la visualidad de los activistas del documental de Lucía Egaña. El propósito de los filmes de Lust es más modesto en su imaginería, pero no menos crítico en su alcance transformador de las políticas sexuales.

Si el porno queer "se opone a todas las categorías identitarias" (Butler 2004: 7), incluidas las más estables, el cine de Erika Lust no pretende disolver por completo los géneros ni los sexos, aunque se apunta a difuminar la estabilidad de sus fronteras. Su cine todavía queda del lado de la excitación placentera no sexista, donde la relación con otros cuerpos sea consensuada, igualitaria, democrática, respetuosa. Si el integrante de Quimera Rosa afirmaba que sus performances no tenían el objetivo de excitar sino de cuestionar lo existente, la directora quiere principalmente excitar sin complejos de culpabilidad (Lust 2015b: s.p.). Sus personajes y sus géneros siguen siendo reconocibles, con manifestaciones del deseo sujetas, más o menos, a lo esperable. Al mismo tiempo, se mantiene una actitud reprobadora de las identificaciones cerradas entre sexo y género, y de los deseos normativos a ellas asociados. Esta actitud es compatible con ese hacerse del género de Butler, en tensión entre la normalización, que solo concibe lo masculino y lo femenino, y el deseo por el reconocimiento de la diferencia más allá de esos dos sexos y géneros.

Sería un error pensar que las propuestas de Preciado son más políticas que las de Lust. Ambos acercamientos se involucran en la redefinición de los entramados simbólicos sobre la sexualidad. Preciado y Egaña los subvierten sin concesiones, mientras Lust los modifica y redefine sin violencias. En el primer caso, elaboran sus posiciones acertadamente desde los márgenes de la normalización heterosexual. Lust, por su lado, amplía los márgenes de lo considerado aceptable al tomar como prácticas placenteras lo rechazado con anterioridad

pentes, Mutantes (2009). A diferencia del de Egaña, Despentes traza el origen del movimiento con entrevistas a activistas postporno, o sexo positivo, en los Estados Unidos. Es de destacar cómo, en la controvertida pero muy destacable película Baise-moi (2000) dirigida por Despentes, los asesinatos se dirigen a todos aquellos hombres y mujeres partícipes, voluntarios o no, de lo heteronormativo y sus juegos de seducción. En este filme, algunas mujeres ejercen violencia fílmica sobre los hombres y no al revés, como ha venido siendo habitual hasta ahora. 
como anormal, desviado o pervertido. Todos, desde sus propuestas teóricas, apean el pensamiento heterosexual de su vocación hegemónica.

Para Lust no hay oposición irreparable con el acercamiento de Preciado. En su Porno para mujeres (2008), la directora dirá que se siente muy afín a lo que Preciado define como "un modo inédito de representar la sexualidad que, retomando la expresión de André Bazin, bien podría denominarse 'nouvelle vague porno'" (2008b: 151). Ella misma afirma sentirse en sintonía con este movimiento, una "pequeña revolución que debe ayudar a transformar el entretenimiento para adultos, llevándolo hacia algo más moderno, aceptable y disfrutable para todos y todas" (151). No obstante, después de contemplar sus películas, es difícil pensar que Lust vaya a involucrarse en la estética de los activistas retratados por Egaña. Su declaración de intenciones ya se apuntaba en el subtítulo de la sección dedicada a esa "nouvelle vague porno": "¿arte, cine, porno o todo a la vez?" (151). Esto es, lo artístico y lo porno no están reñidos sino todo lo contrario. Es más, lo artístico para Lust vendría a ser lo que para Preciado es lo farmacopornográfico, instrumentales críticos de actuación sobre lo existente, dicho sea, salvando las distancias de intencionalidad y objetivos entre ambas.

En cualquier caso, el porno feminista, sexo positivo o postporno de Lust, hace suya la definición de los editores de The Feminist Porn Book: "promueve prácticas estéticas y éticas que intervienen en la representación sexual dominante y movilizan una visión colectiva a favor del cambio" (Taormino et al. 2013: 15). El corolario de estas prácticas, cuya mirada cuestiona lo dominante y se atreve a descubrir "nuevas maneras de concebir el género y la sexualidad" (15), es político, pues apunta a la figuración y conformación de imaginarios sobre lo sexual más acordes con un deseo sin discriminaciones ni exclusiones de ninguna clase. Sobre cuáles serán estas prácticas y cómo se definirían, se apunta a continuación.

¿Qué es y en qué consiste el porno feminista para Erika Lust? Es un "medio de excitación, educación y placer" (Lust 2015b: s.p.). Ni la excitación queda limitada a unas pocas imágenes impregnadas de ardor genital, ni la educación sexual se reduce a los medios mecánicos de procreación, ni el placer se restringe al momento del orgasmo. El enfoque feminista es más necesario que nunca, pues "si se retrata sexo en el cine convencional se hace como si fuese algo sucio, peligroso, problemático o enfermo", y las mujeres que buscan su placer, sin tener que pedir perdón por ello, "casi siempre acaban violadas, heridas, embarazadas o muertas" (Lust 2008b: 94). Los supuestos peligros de lo alternativo femenino han de cauterizarse con la mayor de las violencias. Así, las mujeres han de someterse a los cauces sexuales de sumisión propuestos por lo dominante. Los atrevimientos femeninos -o de cualquier deseo no normativo dentro de la amplia panoplia de lo transexual- a favor de un placer no mediado por el varón heterosexual han de ser reconducidos, sin importar el coste, a la función subordinada de la que nunca debieron atreverse a salir.

Los intentos rupturistas del porno machista no abren tampoco espacios a la sexualidad femenina alternativa. No alivian la situación de dominación de mujeres y géneros no normativos. Más bien han reproducido los mismos esque- 
mas opresivos. Las prácticas sexuales femeninas que no han sido fiscalizadas por miradas de dominación y control son eliminadas. En esta línea, siguiendo a la directora, las mujeres en el porno sexista

... estábamos representadas como zorrillas, adolescentes cachondas, niñeras obsesionadas con el sexo, amas de casa desesperadas, enfermeras calientes y ninfómanas, siempre al servicio de mafiosos, proxenetas, traficantes de drogas, multimillonarios o máquinas sexuales, con el único objetivo de complacerlos a ellos [...] ¿dónde estaban representados mis valores, mi sexualidad y sobre todo mi estilo de vida? (Lust 2015b: s.p.)

Tan asfixiante es la ideología de la reproducción sin placer de cuerpos enfundados en ásperos camisones como la otra del placer porno a base de cuerpos imposibles, dirigidos únicamente a la mirada masculina. Tantas carencias muestra la visión puritana como la del porno machista.

Por lo tanto, "es importante que el porno para mujeres sea producido y dirigido por mujeres [...]. Somos seres integrales y holísticos, tenemos en cuenta detalles, situaciones, fantasías, sugerencias, escenarios" (Lust 2015b: s.p.). Además, "el cásting, la decoración, el estilismo, la ropa interior, la música, el guion, la fotografía [...] son una parte muy importante de mis películas" (s.p.). Esta descripción separa radicalmente las películas de Lust de las del porno tradicional. En una entrevista con Mikel López Iturriaga (Lust 2013), la directora hablará de escenas centradas en torno al placer de las mujeres, y de cómo el punto de vista de la cámara es el adoptado por el personaje femenino. Por otro lado, su estética está más relacionada con el cine erótico e independiente que con el pornográfico. Además, Lust controla la producción de sus películas "contratando a actores que quieren estar en el sitio donde están, que tienen todos los papeles en regla y que han pasado los tests de enfermedades" (Lust 2013: 22). En estas condiciones, y en opinión de la directora, se genera un "ambiente muy bonito de grabación" (22).

No es verdad que su cine, como señala Sayej, sea "afectadamente artístico, como el equivalente porno del buen gusto" (2016: s.p.). Las categorías de buen gusto, o buen tono, son las que restringen la imaginación confinándola a las reglas del decoro en la representación, lo cual no significa dejarse seducir por la simple transgresión si esta no es del agrado de quien dirige una película o de la audiencia que la consume. El porno feminista para Lust es fuente de descubrimiento y reconocimiento de zonas erógenas más allá de los genitales; de excitación más allá de la penetración inmediata de orificios corporales; y de educación sobre el potencial del cuerpo para el placer cuando se lo adereza con la palabra de las confesiones o de las fantasías. Todos sus personajes exploran su sexualidad lejos del miedo, el remordimiento, la culpa o la vergüenza (2008b: 
36). ${ }^{14}$ Como dice Gabriella Wiener, "a las protagonistas de Erika el sexo las libera. A las de James [E. L. James], las esclaviza" (2005: s.p.). ${ }^{15}$

En oposición a las feministas anti-pornografía como Andrea Dworkin, Lust se distancia de esa mirada principalmente puritana y sesgada de moralina. Dworkin hizo famosas algunas de sus visiones, desde que la pornografía es "la descripción gráfica de las mujeres como putas" hasta que en la pornografía "la degradación de las mujeres se tiene como el verdadero placer" (Dworkin 1979: 200). La directora probablemente estará de acuerdo con el análisis de Dworkin en relación con el porno sexista, pero no con la prohibición del sexo explícito ni con los aspectos anti sexo de Dworkin. Para Lust, el porno feminista "respeta la figura de la mujer, no la humilla ni la trata como una puta y una víctima [...] acepta el papel de la mujer como ser sexual activo y [...] es interesante tanto a nivel visual como de diálogo y argumento" (2008b: 76). Contrariamente al análisis de Dworkin, el placer queda en manos de figuras femeninas que han hecho los deberes y las lecturas sobre la opresión sexual patriarcal. En palabras de la directora, "no queremos que nos retraten como objetos pasivos o víctimas, sino como sujetos activos, dando placer y recibiéndolo. Queremos ver a otras mujeres disfrutando" (2008b: 40).

Es más, este cine es una fuente de imaginación sexual femenina, que tratará "sobre intimidad y relaciones", mientras que "el de ellos" solo trata "sobre enculadas y eyaculaciones" (Lust 2008b: 21). En uno de sus primeros filmes, Barcelona Sex Project (2008), definido como "documental erótico" (2008b: 141), la sexualidad de cada personaje guarda estrecha relación con su vida; son inseparables la una de la otra. El orgasmo no surge en el vacío sino que es el resultado de la conjugación de vida, imaginación y deseo. En palabras de la autora, en Barcelona:
... propongo una mirada íntima e independiente a la vida de tres hombres y tres mujeres para conocerles en profundidad, incluidos sus orgasmos reales. Ellos y ellas nos muestran sus pensamientos, pasiones y reflexiones en una entrevista en profundidad; también se llevan una cámara a su vida de cada día para re- tratarla con naturalidad, y finalmente nos invitan a asomarnos a su placer más privado e íntimo, una escena de masturbación. (Lust 2008b: 141)

Este y otros filmes de Lust, como la serie de Xconfessions -ya por su octava entrega y financiado a través de donaciones particulares vía la red- hacen suya la máxima de los editores de The Feminist Porn Book, la de embarcarse en

\footnotetext{
14 Lejos de esos referentes, de acuerdo, pero ¿se marcarían o no límites? La actriz postporno francesa Ovidie no le haría ascos a la estética totalitaria y a sus violencias, lo cual no significa abogar por ella en la vida política $(34,35)$. En entrevista con Michela Marzano, esta última criticará la violencia como fuente de excitación o de deseo (Ovidie: 89).

15 La referencia es al fenómeno editorial Fifty Shades of Gray (2011), y sus correspondientes secuelas, escrita por E. L. James. En estas novelas, la realización de las fantasías tanto masculinas como femeninas está sujeta la mayoría de las ocasiones a la guía del varón heterosexual. De aquí, que más que liberarlo, el deseo femenino quede secuestrado por su dependencia casi única de lo masculino.
} 
la construcción del deseo erótico más allá de lo heteronormativo, el matrimonio, la pareja monógama y la reproducción (Taormino et al. 2013: 14). Por supuesto, cada uno puede elegir la modalidad que más le convenga. De hecho, en la serie de las Xconfessions se filman fantasías privadas, compartidas con los miembros del blog de la directora fuera de esas cuatro instituciones de control.

En las películas de Lust, los preliminares tienen tanta o más importancia que el momento del clímax, como ocurre en "Fantasías orientales" (2016b) o "Chicazo" (2015c). En esta última confesión, una mujer interpreta un número de desnudo integral delante de un hombre, pero ella ha pagado a este hombre para que se masturbe. La mirada ya no es masculina ni el control tampoco. El ritmo del desnudo está controlado por la figura femenina. En "I found your mother on Tinder" (2015c), la mujer madura ha contratado los servicios sexuales de un hombre muy joven, amigo de su hijo. Ella dirige la escena, indicando a la figura masculina cómo y cuándo tocarla, acariciarla o penetrarla. El placer sexual femenino tiene prioridad, y las figuras masculinas practican siempre sexo oral a las femeninas, no a la inversa. El placer buscado con la boca tiene también lugar entre personajes femeninos. En la divertida "Try my boyfriend" (2016b), con los colores chillones característicos de algunas películas de Pedro Almodóvar, una mujer compartirá desinteresadamente a su novio con sus amigas. La preocupación primera del novio es la de proporcionar placer a las amigas de su novia. Otras veces, la figura masculina no es necesaria y la mujer es independiente y autónoma para proporcionarse el placer que desee. En "Be a hero" (2016b), una mujer grabará sus momentos de intimidad en la bañera en un vídeo que posteriormente enviará a su novio. La práctica del sexo anal femenino no dependerá de la voluntad del macho hormonado de turno por horadar una cavidad más de la mujer. Por el contrario, en "The surrender" (2016b), la mujer dirige las manos del hombre para excitar y agrandar sus esfínteres con un dildo, primero, y después con el pene. No parece haber preocupación por la excitación masculina hasta que la mujer se siente cómoda con esta práctica.

Los cuerpos masculinos son siempre normativos, si bien es verdad que muy lejos de las anomalías musculares a base de cirugía y medicación del porno tradicional. Los cuerpos femeninos se salen a veces, no siempre y no demasiado, de los estándares sobre belleza y tamaño corporal. ${ }^{16}$ Por ejemplo, en "How big is Don Draper's cock" (2015c), la protagonista femenina no siente vergüenza alguna, como debe ser, de sus kilos de más. Como tampoco lo sienten la mujer madura de su cuerpo con arrugas en "I found your mother on Tinder" (2016b) o la protagonista femenina en "\#Skype sex" (2015c) de su dentadura sin sonrisa perfectamente alineada. En esta secuencia, la pareja la forman personajes de distinta etnicidad, como ocurre por igual en "My moaning neighbor" (2016b).

La lista de posibilidades exploradas en los filmes de Lust es ciertamente larga. No se olvida de prácticas sado-masoquistas o BDSM (2016a), de la pan-

\footnotetext{
16 Ventura Pons sí se ha atrevido a filmar la sexualidad más o menos explícita entre personas con cuerpos muy alejados de los estándares al uso sobre belleza o tamaños, mostrándolas sin falsos pudores. Mil cretins (2010) sería una de esas películas.
} 
sexualidad (2015c) o del uso de todo tipo de juguetes, o de las posibilidades excitantes de la comida y la bebida.

No importa lo que se explore siempre y cuando se sigan las directrices de Candida Royalle en sus filmaciones de porno feminista, como hacen las filmaciones de Lust. Según Royalle, este ha de tener integridad y ser respetuoso con los actores, sin someterlos a prácticas denigrantes o no consentidas; no ha de ser sexista, y no utilizar el cuerpo femenino, u otros, como instrumentos de placer; y tiene que hacer sentir a las personas bien, a gusto con su cuerpo y sus fantasías (2013: 84).

El cine de Lust elimina del placer los pesados barnices del pecado, del remordimiento, cuando hacen sentirse culpable por haber disfrutado. Sus películas "desafían las representaciones dominantes sobre el género, el placer y el poder" (Taormino et al. 2013: 9), eso sí, acorde con el proyecto fílmico de la directora, sin prestar atención a los profetas y legitimadores intelectuales de visiones únicas sobre cómo debe ser el postporno. La máxima es que "todos tenemos derecho al placer" (84), individual o con otros, a la diversión libre y sin ataduras.

Reclamar este derecho al placer es ya un proyecto político. Se encamina a desarrollar la economía libidinal frente a la economía productiva donde el cuerpo, sus deseos y afectos desaparecen bajo las razones de la eficiencia y de la productividad. En los filmes de Lust se potencia la capacidad para el placer del cuerpo frente a las obligaciones y opresiones del deber social; se incita al disfrute del tiempo libre frente a las rigideces de horarios laborales; se construye el tiempo variado, heterogéneo, de las sorpresas de lo sexual frente a las rutinas del tiempo de trabajo; se preocupa por las necesidades de disfrute de cada uno frente a su sola satisfacción con las promesas del consumo, que terminarán sin excepción en la mayor de las frustraciones. Su proyecto es político por criticar el neoliberalismo económico desde la liberación de lo sexual de las ataduras de la eficiencia o de la productividad del cuanto más, mejor. Con otras palabras, una sexualidad restrictiva, opresiva, elaborada a base de tapujos y malas conciencias, deja su lugar a otra centrada en la exploración del deseo propio. En la sexualidad reflejada en los filmes de Lust, el cuerpo no es lugar de producción -ni siquiera de producción orgásmica-, sino de relación placentera con los demás. Sin falsas moralinas ni alegatos ideológicos, sus personajes hacen suyo el deseo de Virginie Despentes de no dejar que sus sexualidades sean "confiscadas, vigiladas, normalizadas" por policías, estados o religiones (2009: 95). Si lo consiguen o no, dependerá del grado de aceptación de sus propuestas por parte del espectador.

\section{OBRAS CITADAS}

Agamben, Giorgio (2011): Desnudez [Nuditá, 2009)]. Trad. Mercedes Ruvituso y María Teresa D'Meza. Barcelona, Anagrama.

Badiou, Alain, y Truong, Nicolas (2012): In Praise of Love [Éloge de l'amour, 2009]. Trad. Peter Busch. Nueva York, The New Press. 
Breillat, Catherine (2009): Anatomy of Hell [Anatomie de l'Enfer, 2004]. DVD. Los Angeles, CA, Palisades Tartan Video.

Butler, Judith (2004): Undoing Gender. Nueva York, Routledge.

Byung-Chul, Han (2014): La agonía del Eros [Agonie des Eros, 2012]. Trad. Raúl Gabás. Barcelona, Herder. E-book.

Byung-Chul, Han (2013): La sociedad de la transparencia [Transparenzgesellschaft, 2012]. Trad. Raúl Gabás. Barcelona, Herder. E-book.

Cavarero, Adriana (2009): Horrorism: Naming Political Violence [Orrorismo: Ovvero della violenza sull'inerme, 2007]. Trad. William McCuaig. Nueva York, Columbia University Press.

Cheang, Shu Lea (2009): I.K.U. [2000]. DVD. París, K Films.

Despentes, Virginie (2011): Mutantes: Punk, Porn, Feminism. [2009]. DVD. Kino Lorber.

— (2009): King Kong Theory [King Kong Théorie, 2006]. Trad. Stéphanie Benson. Londres, Serpent's Tail.

(2000): Baise-moi. DVD. Canada, Remstar.

Dworkin, Andrea (1979): Pornography. Men Possessing Women. Nueva York, A Perigee Book.

Egaña Rojas, Lucía (2011): Mi sexualidad es una creación artística (A Documentary About PostPornography), accesible en <http://sectapodrida.blogspot.com/2016/05/misexualidad-es-una-creacion-artistica.html> [última visita: 11.5.2016].

— (2009): "La pornografía como tecnología de género. Del porno convencional al postporno. Apuntes free-style". En lafuga.cl, accesible en <http://www.lafuga.cl/la-pornografia-como-tecnologia-degenero/273> [última visita: 9.7.2015].

Godard, Jean-Luc (2005): Tout va bien [1972]. DVD. Chicago, Home Vision Entertainment. hooks, bell (2000): Feminism is for Everybody. Passionate Politics. Cambridge, South End Press.

James, E. L. (2011): Fifty Shades of Gray. Nueva York, Vintage Books.

Kristeva, Julia (1982): Powers of Horror. An Essay on Abjection [Pouvoirs de l'horreur, 1980]. Trad. Leon S. Roudiez. Nueva York, Columbia Universtiy Press.

Lauretis, Teresa de (1990): "Eccentric Subjects: Feminist Theory and Historical Consciousness", Feminist Studies, vol. 16, n. ${ }^{\circ} 1$, pp. 115-50.

Lavigne, Julie (2014): La traversée de la pornographie: politique et érotisme dans l'art féministe. Montréal/Québec, Les Éditions du Remue-Ménage.

Lyotard, Jean-François (1993): Libidinal Economy [Economie libidinale, 1974]. Trad. Iain Hamilton Grant. Bloomington, Indiana University Press.

Lust, Erika (2016a): XConfessions 7, accesible en <http://www.erikalust.com> [última visita: 1.1.2016].

- (2016b): XConfessions 6, accesible en <http://www.erikalust.com> [última visita: 1.1.2016].

_ (2015a): Let's Make a Porn. A Practical Guide to Filming Sex, accesible en <http://www. erikalust.com> [última visita: 7.5.2015].

— (2015b): <http://www.erikalust.com> [última visita: 7.5.2015].

— (2015c): XConfessions 4. erikalust.com [última visita: 1.1.2016].

— (2013): "Quiero trabajar con gente que no respire pornografía." Entrevista de Mikel López Iturriaga. En El País Semanal 14 de agosto), pp. 19-25. 
— (2008a): Barcelona Sex Project. http://www.erikalust.com. Última visita 2016.

— (2008b): Porno para mujeres. Barcelona, Editorial Melusina. E-book.

Marzano, Michela (2003): La pornographie ou l'épuisement du désir. Paris, Buchet/Chastel.

Ovidie (2005): Films X: y jouer ou y être? Le corps acteur. Ovidie, un entretien avec Michela Marzano. París, Éditions Autrement.

Pérez, Kim (2010): "Historia de la patologización y despatologización de las variantes de género". En Miquel Missé y Gerard Coll-Planas (eds.): El género desordenado. Críticas en torno a la patologización de la transexualidad. Barcelona/Madrid: Editorial Egales, pp. 97-111.

Pons, Ventura (2011): Mil cretins [2010]. DVD. Barcelona, Cameo Media.

Preciado, Paul (2011): Manifiesto contrasexual [Manifeste contra-sexuel, 2000]. Trad. Julio Díaz y Carolina Meloni. Barcelona, Anagrama.

— (2008): Testo yonqui. Madrid, Espasa Calpe.

Royalle, Candida (2013): "What's a Nice Girl Like You...". En Tristan Taormino, Celine Parreñas Shimizu, Constance Penley y Mireille Miller-Young (eds.): The Feminist Porn Book. The Politics of Producing Pleasure. Nueva York, The Feminist Press, pp. 58-69.

Sayej, Nadja (2016): "A Women's Fight to Prove Porn can be Feminist", accessible en <http:// www.newsweek.com/feminist-porn-lives-434511?rx=us> [última visita: 29.3.2016].

Taormino, Tristan; Parreñas Shimizu, Celine; Penley, Constance; Miller-Young, Mireille (eds.) (2013): The Feminist Porn Book. The Politics of Producing Pleasure. Nueva York, The Feminist Press.

Torres, Diana (2011): Pornoterrorismo. Tafalla, Txalaparta.

Virilio, Paul (1996): Politics of the Very Worst. An Interview by Philippe Petit [Cybermonde, la politique du pire: entretien avec Philippe Petit]. Ed. Sylvère Lotringer. Trad. Michael Cavaliere. Nueva York, Semiotext(e).

Wiener, Gabriella (2005): "Se firman fantasías sexuales. Razón aquí", El País-Tentaciones, accesible en <http://elpais.com/elpais/tentaciones.html> [última visita: 25.8.2005].

Williams, Linda (1989): Hard Core: Power, Pleasure, and the Frenzy of the Visible. Berkeley, California University Press. 